\title{
Strategic human capital resources: a brief history, construct definition, and introduction to the Handbook of Research on Strategic Human Capital Resources Thomas P. Moliterno and Anthony J. Nyberg
}

\section{INTRODUCTION}

This volume is about human capital resources (HCRs). Since the HCR construct is a newcomer to a long-standing literature on human capital (Becker, 1964), we begin with a brief historical thumbnail review of the history of research on HCR. We do so to provide a quick orientation to the focus of this volume: it is neither our intention nor hope to be exhaustive in this regard. Over the past 20 years, there has been an increasing convergence of scholarly disciplines exploring the association of human capital and organizational performance. Early gatherings at the Wharton School of the University of Pennsylvania and the University of Utah brought together arrays of scholars from diverse backgrounds who were interested in exploring the organizational effects and antecedents of human capital. As scholarly discourse at the intersection of these fields grew, researchers from strategic human resource management (HRM) and strategy disciplines combined to create the Strategic Human Capital Interest Group that first met in Rome in 2010 and has been one of the faster-growing interest groups of the Strategic Management Society (SMS).

At this point, the HCR construct had not yet been articulated and defined. Its genesis came from the realization that the human capital construct had begun to take on different meanings in different literatures. Many scholars thought of human capital as something specifically owned by workers (i.e., "the individual's human capital"), while others were focused on how workers contributed to organizational performance (i.e., "the firm's human capital"). That is, some researchers (predominantly from the "micro" traditions of organizational behavior, organizational psychology, and human resource management) focused on the "human" and some researchers (predominantly from the "macro" traditions of strategy and economics) focused on the "capital." Hence the term "human capital" was simultaneously being used too broadly, including all firm-level phenomena involving workers, and too narrowly, missing how individual differences in knowledge, skills, abilities, and other characteristics (KSAOs) help define the value of the worker to the firm.

A central cause of this tension also proved to offer a path to resolving it. Early strategic HRM research by Wright and McMahan (1992) invoked macro-level resource-based theory (RBT) from the strategy literature (Barney, 1991) to suggest the strategic value of the firm's human resources and the policies and practices used to manage them. In the macro literature, Hitt et al. (2001) extended this logic by arguing that the firm's human capital was a strategic resource. Thus, the same theoretical perspective and framing were being used in different literatures, but these different literatures rarely spoke to each other. And yet it was this shared theoretical perspective that suggested a path forward for 
the theoretical integration of multiple levels of analysis in our understanding of human capital. Ployhart and Moliterno (2011) articulated this integration and introduced the term "human capital resource" (HCR) as a unit-level construct. ${ }^{1}$ This work posited that important insights flowed from the convergence of "micro" and "macro" perspectives on the relationship between human capabilities and organizational performance, with the lynchpin being the mechanisms by which a firm-level HCR emerges (Kozlowski and Klein, 2000) from a collection of individual-level human resources. Shortly thereafter, Nyberg et al. (2014) undertook a comprehensive review of the strategic HRM and strategy literatures, mapping prior findings onto a new multidimensional and multilevel HCR framework.

Indeed, 2014 was a watershed year for research on HCRs. In addition to the review by Nyberg et al., there was a special issue of the Journal of Management (Wright et al., 2014). One of the articles in that issue developed the HCR construct still further. Ployhart et al. (2014) declared "human capital is dead; long live human capital resources" and argued that HCRs could be conceptualized and observed at both the individual and unit level. Importantly, in this article Ployhart et al. formally define "human capital resource" (more on this below), thereby permanently entering the term into the canon. This article attempted to pull from a broad set of theoretical backgrounds to establish a clear definition of HCRs. It further worked to explain and differentiate relevant terms from KSAOs to human capital to HCR to strategic HCR. The paper also went on to describe how each of these constructs can be created, and their relative benefits for individuals and units. Scholars also gathered at the University of South Carolina in 2014 to discuss bridging the language divide between micro and macro perspectives, and an associated special issue publishing the lessons learned (Nyberg and Wright, 2015).

Shortly thereafter, we were approached with the opportunity to edit a volume for the Edgar Elgar Handbook series, and we knew that this provided an opportunity to create a volume that could focus on HCRs: exploring this rapidly evolving field, articulating and illustrating ongoing theoretical tensions, and suggesting research to move the field forward. And so we set out to design a conversation about HCRs that spanned levels of analysis, scholarly disciplines, and theoretical domains. Of course, that presumed that we could ourselves agree on an HCR definition. And this will be no surprise to our colleagues who know us: we couldn't.

\section{DEFINING STRATEGIC HUMAN CAPITAL RESOURCES}

The most interesting and fun aspect of developing this book was the tremendous willingness for the leading voices in the field to join the efforts to discuss this topic. One activity involved bringing authors together (hosted by the University of Maryland in May 2018). During this gathering - which was notable for the civil and challenging discourse that occurred, as well as the willingness for extremely successful scholars to truly listen and learn - what emerged was the recognition that many people working in this area differ in how they understand, define, and operationalize the HCR construct. Indeed, we came to realize that even we did not see eye-to-eye about some of the underlying assumptions in an area that we have worked on together and with others for over a decade. Hence, as much as for ourselves as for readers of this volume, we begin by defining the HCR construct. 


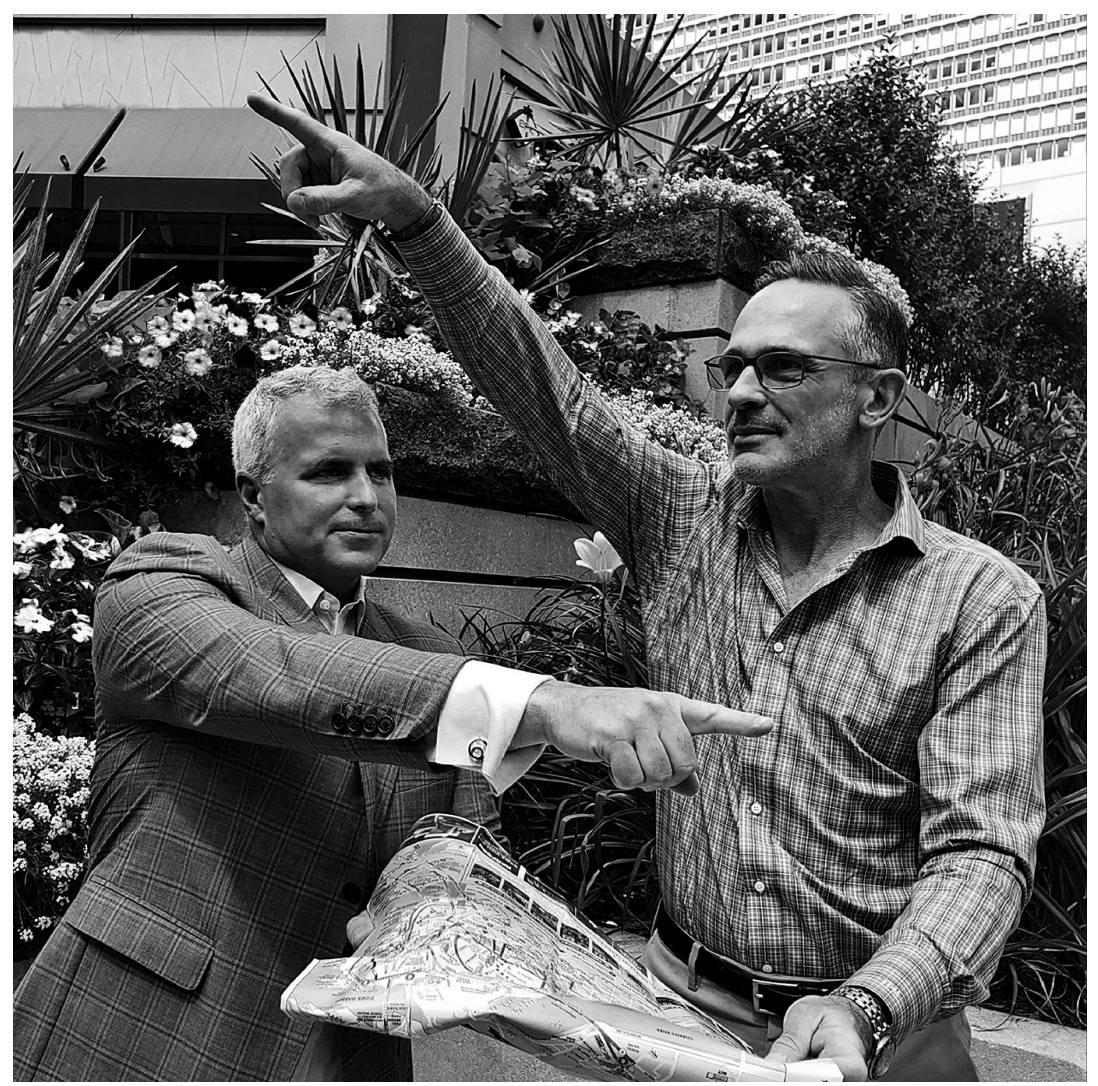

Figure I.1 The editors, as once photographed by Sekou Bermiss, disagreeing as usual

The main difference between the traditional view of human capital (Becker, 1964) and the perspective on HCRs suggested by Ployhart and Moliterno (2011) is the explicit focus on the organization as the level of theory: "we define human capital as a unit-level resource created from the emergence of individuals' [KSAOs]" (2011: 127-8). As noted above, Ployhart et al. elaborated on this by formally defining HCRs to include the individual level of theory and analysis: "Human capital resources are individual or unit-level capacities based on individual KSAOs that are accessible for unit-relevant purposes" (2014: 374). The most notable difference between these two perspectives is the place of the individual. Ployhart and Moliterno understand the individual as component to the unit-level HCR, whereas Ployhart et al. understand the individual as an HCR sui generis. This non-trivial difference notwithstanding, these two definitions share a number of areas of similarity. Both recognize that the unit-level resource comprises individual-level components, and both invoke a resource-based theoretical framing.

Most importantly, both papers conclude that HCRs can be "strategic," that is, a source of differentiated unit-level performance outcomes and (ultimately) competitive advantage. In Ployhart and Moliterno, this strategic resource exists only at the firm level. In contrast, Ployhart et al. suggest that the individual-level HCR can also be a strategic 
HCR. For many years, this has been a point of disagreement between us. Resource-based theory (Barney, 1991) describes how a firm-level resource can be leveraged for competitive advantage: how should we think about applying that theoretical proposition at the individual level? Is this not a "cross-level fallacy" (Rousseau, 1985) as described in Ployhart and Moliterno? In the course of the conversations that lead to this book we have resolved this question to our mutual satisfaction, and find that the answer to this puzzle illuminates an interesting boundary condition to our theorizing.

Before we delve into that, however, it is useful to explore a number of concepts that are important to understand when thinking about HCRs. To summarize briefly, when we think about the individual's KSAOs, then human capital is the correct term. However, when we talk about human capital from the unit's (e.g., firm, team, and department) perspective, then we are talking about HCRs. To the extent that we are tying the HCR to unit-level performance outcomes, then we are considering strategic HCRs (SHCRs). Broadly speaking, and from their own vantage, this is the topic that we asked the leading experts in the field to write about in this book.

\section{The Individual and Unit Level}

The HCR is a multilevel construct. Both Ployhart and Moliterno (2011) and Ployhart et al. (2014) agree that at the firm level the HCR comprises aggregations of individuals and their unique configurations of KSAOs. In the initial formulation, Ployhart and Moliterno did not label these individuals "human capital resources" per se. Rather, they argued that "the roots of human capital lie at the individual level and exist in the full range of employees' KSAOs" (2011: 132). That is, in their model, the individual employee contributes components of the unit-level HCR by drawing on their respective KSAO endowments, and the unit-level HCR emerges (Kozlowski and Klein, 2000) through the combination of these component KSAOs.

Ployhart et al. (2014) extended this line of thinking to argue that HCRs do not exist only at the unit level as combinations of individual KSAOs. Rather, the individual employee herself could be an HCR. That is, an individual could leverage her KSAOs in such a way that she - as an individual - becomes a resource that can be a source of firm-level performance. Thus, individuals are (or can be) both HCRs and components of HCRs. At the individual level the knowledge within a single domain of a single scientist working in the unit is an example of an individual-level HCR. By this definition, an individual's accessible and relevant KSAOs have potential to be a unit's HCR. The HCR is also the portfolio of complementary skills possessed by a group of individuals. For example, the collection of people working in a marketing department constitute an HCR, as does the shared capability for joint production that can be enacted by a small group of production operators. Hence, although not clearly articulated in Ployhart et al. (2014), the term HCR can be used to describe subparts of a firm's people-related resources (i.e., individual HCRs), the totality of those resources (i.e., unit-level HCRs), or both.

In sum, HCR theory necessarily starts with individuals. The firm comprises a collective of people who individually act - hopefully in a coordinated way - to pursue the organization's goals and objectives. Accordingly, we note that it is important to remember that individual people take action: when we are considering individual HCRs this is obvious. And since it is still individuals who act when we consider the HCR as a unit-level resource, 
unit-level HCRs should not be thought of as actors per se. Individuals act both alone and together with varying degrees of motivation toward a variety of objectives. It is the collection of these actions that lead to firm-level performance, and ideally competitive advantage. We will return to this momentarily.

\section{Accessibility of HCR Capacities}

While individuals and the human capital embedded in their KSAOs are at the foundation of all HCRs, it is important to note that it is the productive capacities that the KSAOs make available to the organization - and not the KSAOs per se - that associate with firmlevel outcomes. This is an important distinction and theoretical extension articulated in Ployhart et al. (2014) that hews closely to Penrose's (1959) early insights regarding the strategically important "services" provided by the firm's human resources. Thus, while HCRs are assets that the firm leverages to produce its products and services in ways consistent with the underlying resource-based theory (Barney, 1991), the HCR is not just another resource. The value in HCRs is the useful productive capacities that they make accessible to a unit. Simply put, for the HCR to be a valuable resource, individuals must perform.

Given this, the firm can only leverage the value created by the HCR if it can access their KSAO-based productive capacity; and it can only access that capacity if individuals apply it in service of the firm's strategic priorities and direction. The question then becomes one of the mechanisms by which the firm can access the productive capacities latent in HCRs. Given what we know about the complexity of individuals and groups (e.g., Coff, 1997), it is easy to extrapolate that this complexity will make these mechanisms very important and interesting. Very often, the ability to access these capacities becomes a question of complementarities (Milgrom and Roberts, 1995; Adegbesan, 2009): identifying the other organizational practices or resources that can be combined with the focal HCR to create unique value (also see Morris and Snell, Chapter 12; Crocker, Chapter 13; Wright and Essman, Chapter 14; and Brymer and Hitt, Chapter 15).

At the individual level, human resource management policies and practices can be structured and implemented in such a way as to access these KSAO-based capacities. For instance, Nyberg and Reilly (Chapter 23) argue that pay strategies play a crucial role in the degree to which the capacities described by the HCR are enacted by people to yield performance outcomes for units.

There are also mechanisms for KSAO-based capacity accessible at the unit level. Crocker (Chapter 13) explores how social capital within the unit interrelates with HCR value creation, suggesting a social mechanism for capacity accessibility. In fact, even how the unit-level HCRs are created and structured can affect the accessibility of these capacities: Ployhart and Moliterno (2011) describe an "emergence enabling process," and Ployhart et al. (2014) articulate different "human capital resource combinations." Crocker also examines how "external social capital" can provide access to HCRs outside the firm, suggesting that we should not focus only on mechanisms for accessing KSAO-based capacities provided by people who work in the firm. Accordingly, the HCR construct is broader than it may seem at first glance since it can include the KSAOs of people who do not work inside the unit but whose skills are accessible to the unit.

There is a necessary limiting implication of these thoughts on accessibility. Consider an individual working in a unit who has a particular skill or knowledge that represents 
a valuable capacity for the firm. The fact that they possess that skill is not enough to describe that individual, or the unit in which they participate, as an HCR. To the extent that the skill of an employee is inaccessible to the unit it cannot be considered an HCR. Thus, just as there are mechanisms that make a KSAO-based productive capacity accessible, so too are there mechanisms that make it inaccessible: a lack of discovery of the capacity by leaders; a lack of motivation to use the capacity by the employee; or the lack of the complementary resources needed to make the capacity usable in a specific context. It is this enactment by people of capacity into reality that is one of the key differences between human capital and other resources. Whereas the prescribed capacity of a machine resource can be expected to be realized regularly (as long as regular maintenance is conducted), we can expect that realization of a human's productive capacity will be more variable.

\section{Unit-Relevant Purposes ... and a Puzzle}

The final dimension of the HCR that merits some discussion is the "unit-level purposes" for which the firm leverages the HCR's productive capacities. Ployhart et al. note that "while specific purposes are idiosyncratic to individual units, most aim to create value for various stakeholders and in many cases by winning in competitive markets" (2014: 379). Thus, in keeping with the underlying RBT (Barney, 1991), our definition of HCRs includes performance outcomes at the unit (i.e., often the firm) level. Ultimately, all the foregoing discussion regarding the individual's KSAOs, capabilities, and accessibility relates to the ability of the HCR to provide some sort of value - usually economic - to the organization.

Of course, this hews closely to the central questions in the strategy discipline: what drives performance differences among firms; and how do firms achieve superior performance (i.e., "competitive advantage") relative to other firms in their industry? RBT (Barney, 1991) suggests that the answers to these questions lie in the firm's resource configuration. A review of this theoretical perspective and its application to the human capital literature is likely unnecessary for readers of this chapter. To oversimplify: RBT's response to the core strategy question is - the firm's resource configuration. Thus a "strategic" resource is one that is associated with firm performance and, ideally, competitive advantage.

Scholars working in the human capital literature have drawn on this RBT scaffolding as the foundation for their work, and Ployhart et al. made the specific connection to HCRs: "[HCRs] can be housed across all levels of an organization. There is a difference between strategic [HCRs] that are relevant for competitive advantage and fit the RBT framework and [HCRs] that can be beneficial for unit performance at all levels" (2014: 390). Inasmuch as they argue that HCRs are created at the individual and unit level, Ployhart and colleagues conclude that "strategic human capital resources can exist at all levels" (2014: 391). That is, both individual- and unit-level HCRs can be associated with unit-/firm-level performance.

As we noted earlier in this chapter, this component of the HCR framework has been central to a disagreement we have had for years. The core of this disagreement concerns how we should think of the levels of theory (Kozlowski and Klein, 2000; Rousseau, 1985 ) in this context. RBT is a firm-level theory describing how a firm-level resource can be leveraged for competitive advantage - so how should we think about assuming 
isomorphism and applying that theoretical proposition at the individual level? Do we not create a "cross-level fallacy" (Rousseau, 1985) as described in Ployhart and Moliterno (2011) when we apply the firm-level theory to an individual-level resource, and then argue that the individual-level resource associates with unit-level performance outcomes (let alone firm-level competitive advantage)?

As we prepared this volume, we discussed this on a number of occasions and came to agree that the arguments in Ployhart et al. (2014) apply only if and when we consider the individual-level HCR a unit-level resource. That is, if we consider the individual-level HCR a unit-level resource, we are operating at the same level of theory, and are on solid ground theorizing an association between the individual-level HCR and unit-level performance. This points to an important boundary condition for the insights articulated in Ployhart et al. An individual can be a strategic HCR when they behave as a firm-level construct: for instance, when there is only one of them in the firm and all their actions occur at the firm level. Examples of this are an entrepreneur in a start-up and a CEO of a major corporation. It is also possible that "a star" scientist (e.g., Call et al., 2015; Kehoe et al., 2018) could be thought of in this manner if we are able to attribute their individual output to unit-level outcomes. If such a scientist is part of a team or a research lab, they are then part of a unit and our comments above about complementarities within the unit apply. That is, we have to assume that some part of their productive output is a function of the complementary HCRs in their unit (and perhaps the social capital; Crocker, this volume). We believe that the kernel of this boundary condition is embedded in Ployhart et al. (2014); and with these comments we hope to make that boundary condition explicit. In any event, this has resolved a long-standing disagreement between us.

\section{OUTLINE OF THIS VOLUME}

The chapters in this book fall into two broad domains of thinking surrounding HCRs: how we conceptualize them and how we actuate them in organizations. Within each of these two broad domains are four parts designed to be conversations about an aspect of HCR from both more micro and more macro perspectives. Each of the four parts is further divided by "starter" chapters that are designed to approach the topic in a creative way, and two "commentary" chapters - one each again from the micro and macro perspectives - that use the starter chapters as a means for exploring the issues.

\section{Conceptualizing HCRs}

The chapters in this half of the book are focused on fundamental questions surrounding how we think about and understand HCRs. As such, the four parts consider value creation, multilevel perspectives, firm-specificity, and complementarities.

\section{Part I Value creation and value capture: rents}

The first part in this half of the book focuses on the value created by HCRs, how that value is captured, and by whom. Conroy (Chapter 1) approaches the topic by considering the role of base pay in understanding the trade-off between the value captured by employees who compose HCR and the value captured by the organization. Bridoux and 
Stoelhorst (Chapter 2) take a different approach by considering alternative mechanisms for governing employment relationships. In their commentary chapters (one of two cases in the volume where the micro and macro authors combined forces due to what they viewed as the shared approach between their respective perspectives) Chadwick and Coff (Chapters 3 and 4) pick up and build on both of these ideas to present an integrated discussion as a holistic means for evaluating the role of rent sharing among the organization's critical stakeholders.

\section{Part II Multilevel approaches: emergence}

This part establishes both a methodological and theoretical approach to thinking about the multilevel nature of HCR and emergence. In their combined starter chapter, Eckhardt and Jiang (Chapter 5) provide an excellent and exhaustive primer on the theoretical and empirical issues surrounding the multilevel nature of HCRs. In their commentary chapters, Kozlowski (Chapter 6) and Cannella and Sy (Chapter 7) explore these same ideas and raise the critical issue of path dependence. They also note the complexities involved in emergence, the difficulties associated with trying to measure emergence, and the necessity of thinking about emergence over time and as a process.

\section{Part III Isolating mechanisms: firm-specificity}

Central to the RBT (Barney, 1991) that is employed in scholarship on HCRs is the notion that the firm-specificity of a resource acts as an isolating mechanism that provides the firm a competitive advantage (Peteraf, 1993). Both of the starter chapters in this section (Weller, Chapter 8; Campbell and Kryscynski, Chapter 9) provide both insights and caution regarding the use and reliance on the construct of firm-specificity in the context of theorizing on HCRs. Weller focuses on the importance of matching as a determinant of firm value, and Campbell and Kryscynski remind us that it may be the system that is responsible for driving value. Commenting on these starter chapters, Delery and Roumpi (Chapter 10) take a broad perspective on thinking about firm-specificity to discuss the (lack of) constraints that firm-specificity may really have and the importance of considering a broader selection of specificities. Lewin and Teece (Chapter 11) tackle this topic from a systems perspective, and introduce the need for involving the dynamic capabilities framework to appreciate how organizations can use HCR to their advantage.

\section{Part IV Complementarities: human and social capital}

Much of the extant research on HCRs notes the challenge of determining where human capital ends and social capital begins (e.g., Ployhart and Moliterno, 2011; Nyberg et al., 2014; Wright et al., 2014; Ployhart et al., 2014). Morris and Snell (Chapter 12) explore this question by taking a customer problem-solving perspective to argue for the importance of considering the relationship between human and social capital, while Crocker (Chapter 13) highlights the inherent and reciprocal relationship between HCR and social capital before, during, and after the emergence of unit-level HCRs. Brymer and Hitt (Chapter 15) take a decidedly different approach by acknowledging that social capital can positively influence HCR, and also introduce the idea that social capital can negatively influence HCR. Wright and Essman (Chapter 14) integrate ideas across chapters to remind readers that social capital and HCR, in combination, influence an organization's ability to compete in the market. 


\section{Actuating HCRs}

This half of the volume moves away from the broad theoretical and nomological network within which HCR theory is embedded, and focuses instead on topics surrounding various manifestations and implications of HCRs in the organizational context. The sections in this half of the volume explore questions surrounding how organizations acquire HCRs, mobilize them as teams, and pay and otherwise incentivize them, and implications of the fact that employees move between organizations.

\section{Part V Building SHCRs: hiring and acquiring}

It is trivial to observe that without hiring employees, the organization cannot have HCRs. What is not at all trivial are the complex theoretical questions surrounding, and critical practical implications of, the recruitment and acquisition of "talent." Kehoe and Bentley (Chapter 16) provide a comprehensive scholarly overview of the selection and mobility literatures, and then incorporate ideas surrounding the "vertical" and "horizontal" fit of employees. Writing from the macro perspective, Camuffo and De Stefano (Chapter 17) approach the topic by questioning some of the conceptual premises posited in the selection literature and outlining four broad strategies for acquiring HCRs. Mackey and Barney (Chapter 18) provide the macro commentary on the two starter chapters, and then integrate insights from transaction cost economics and RBT to provide a framework for thinking about when HCRs should be inside or outside the boundary of the firm. There is no micro commentary in this part: one of the great voices in our field fell silent before he was able to write this chapter. Dave Lepak was an early contributor to HCR theory, and a co-founder of the Strategic Human Capital Interest Group at the Strategic Management Society. He was a co-author, colleague, and/or mentor to many of the contributors to this volume. He was a friend to all of them. We miss you, Dave, and dearly wish you were contributing a chapter on this topic: we know you would have given us something important to think about.

\section{Part VI Mobilizing strategic human capital resources: teams}

Teams are one of the most common and theoretically interesting units in which the emergent HCR can be found. In their starter chapter on this topic, Porter, Amber, and Wang (Chapter 19) provide new theoretical ideas for how to think about goal alignment within teams. The authors examine the challenge faced when individuals' goals differ from each other's and from the team's, and how these differing goals impact performance outcomes. Taking a perspective on teams that is common in the macro literature, Bermiss and Darnell (Chapter 20) focus on the firm's top management team. Taking a new perspective on this literature, the authors raise interesting questions about how top management teams respond to negative events. Ployhart and Chen (Chapter 21), from the micro perspective, and Wiersema (Chapter 22), from the macro perspective, tie these concepts together and push readers to think more broadly about the role of teams in affecting organizational outcomes. Together, these chapters suggest great new opportunities for pursuing team research relevant to HCRs.

\section{Part VII Compensating strategic human capital resources: incentives}

As Coff (1997) notes, the firm's human capital is the only resource that walks out the door every night. Accordingly, the question of incentivizing the HCR to return and remain 
productive is both theoretically and practically important. Nyberg and Reilly (Chapter 23) begin this part with a model that argues that pay is a critical component in the actualization of HCR. Larkin (Chapter 24) follows this by admonishing researchers studying pay to think about the strategic implications of pay and how pay affects the HCR. Addressing the challenges posed in these two chapters, and providing its own perspective, Gerhart (Chapter 25) provides specific commentary on why research involving pay and HCR has, at times, been stilted. This chapter also provides specific suggestions for future research, particularly the need to examine the relationship between pay and performance within a system over time. In the macro-level commentary, Obloj and Zenger (Chapter 26) push readers in a similar direction by explicating how and why HCR research in general, and the study of pay in relationship to HCR in particular, must take a dynamic approach.

\section{Part VIII Keeping strategic human capital resources: mobility}

The concluding part in this half of the book focuses on the organizational reality surrounding the volition of employees to move between organizations. Such mobility necessarily impacts the firm's HCRs. Hausknecht (Chapter 27) provides an exceptional review of the turnover literature, and shows clear connections between mobility and turnover literatures before providing specific guidelines for research that integrates the two. Likewise, Rider and Tan (Chapter 28) challenge the common assumption that turnover equals losses as a mechanism for pointing to how organizational behavior (OB), strategy, and entrepreneurship research can be integrated to advance our knowledge about how inflows and outflows of employees impact the firm's HCR. Bidwell (Chapter 29) builds on the starter chapters to further rethink how we research mobility, and what leaving means for HCR in terms of both disruption and the costs of preventing that disruption. Agarwal (Chapter 30) takes a broader view by looking at how HCR mobility, particularly from an entrepreneurial perspective, is a critical element in understanding firm performance. This chapter argues that we need a stronger connection between micro and macro fields to break down assumptions and to learn from multiple perspectives about the mechanisms at work in employee mobility.

\section{CONCLUSION}

The idea of bringing together scholars from different perspectives is not new. Yet, even in academic disciplines where we strive for rigor and true learning, rarely are differing perspectives embraced - but embrace we must. Indeed, scholarship on HCRs necessitates the integration of multiple perspectives inasmuch as the construct is inherently multilevel and interdisciplinary. Accordingly, our approach to studying HCR must be similarly multilevel and interdisciplinary. Only through the combination of knowledge, analytical techniques, and unique perspectives can the HCR field - which draws from fields ranging from psychology to economics and anthropology to sociology - properly address this interdisciplinary construct (Nyberg and Wright, 2015). As can be seen throughout the book, each author in this collection of extraordinary scholars addresses their own specific topic exceedingly well, but also touches on topics relevant to many other chapters as well. This provides an excellent example of the value that can come through combining the knowledge generated across disciplines, allowing scholars to benefit from the leading 


\section{Handbook of research on strategic human capital resources}

insights and the most enlightened research available. Through the chapters in this book, which combine the voices of leading scholars from a wide range of disciplinary backgrounds, we can identify commonalities: commonalities that we can use as foundational building blocks and opportunities for advancing the field.

\section{NOTE}

1. Consistent with prior work in this literature, we use the term "unit-level" as a generic term to describe any organizational collective. Thus, a firm is a unit, as is a division, a group, or a team.

\section{REFERENCES}

Adegbesan, J. A. (2009). On the origins of competitive advantage: Strategic factor markets and heterogeneous resource complementarity. Academy of Management Review, 34(3), 463-75.

Barney, J. (1991). Firm resources and sustained competitive advantage. Journal of Management, 17(1), 99-120.

Becker, G. S. (1964). Human Capital: A Theoretical and Empirical Analysis, with Special Reference to Education. Chicago, IL: University of Chicago Press.

Call, M. L., Nyberg, A. J., and Thatcher, S. M. B. (2015). Stargazing: An integrative conceptual review, theoretical reconciliation, and extension for star employee research. Journal of Applied Psychology, 100(3), 623-40.

Coff, R. W. (1997). Human assets and management dilemmas: Coping with hazards on the road to resourcebased theory. Academy of Management Review, 22(2), 374-402.

Hitt, M. A., Bierman, L., Shimizu, K., and Kochhar, R. (2001). Direct and moderating effects of human capital on strategy and performance in professional service firms: A resource-based perspective. Academy of Management Journal, 44(1), 13-28.

Kehoe, R. R., Lepak, D. P., and Bentley, F. S. (2018). Let's call a star a star: Task performance, external status, and exceptional contributors in organizations. Journal of Management, 44(5), 1848-72.

Kozlowski, S. W. J., and Klein, K. J. (2000). A multilevel approach to theory and research in organizations: Contextual, temporal, and emergent processes. In K. J. Klein and S. W. J. Kozlowski (eds), Multilevel Theory, Research, and Methods in Organizations: Foundations, Extensions, and New Directions, 3-90. San Francisco, CA: Jossey-Bass.

Milgrom, P., and Roberts, J. (1995). Complementarities and fit strategy, structure, and organizational change in manufacturing. Journal of Accounting and Economics, 19(2-3), 179-208.

Nyberg, A. J., Moliterno, T. P., Hale, D. H., and Lepak, D. P. (2014). Resource-based perspectives on unit-level human capital: A review and integration. Journal of Management, 40(1): 316-46.

Nyberg, A. J., and Wright, P. M. (2015). 50 years of human capital research: Assessing what we know, exploring where we go. Academy of Management Perspectives, 29(3), 287-95.

Penrose, E. (1959). The Theory of the Growth of the Firm. New York: Wiley.

Peteraf, M. A. (1993). The cornerstones of competitive advantage: A resource-based view. Strategic Management Journal, 14(3), 179-91.

Ployhart, R. E., and Moliterno, T. P. (2011). Emergence of the human capital resource: A multilevel model. Academy of Management Review, 36(1), 127-50.

Ployhart, R. E., Nyberg, A. J., Reilly, G., and Maltarich, M. A. (2014). Human capital is dead; long live human capital resources! Journal of Management, 40(2), 371-98.

Rousseau, D. M. (1985). Issues of level in organizational research: Multi-level and cross-level perspectives. In L. L. Cummings and B. Staw (eds), Research in Organizational Behavior (Vol. 7: 1-37). Greenwich, CT: JAI Press.

Wright, P. M., Coff, R., and Moliterno, T. P. (2014). Strategic human capital: Crossing the great divide. Journal of Management, 40(2), 353-70.

Wright, P. M., and McMahan, G. C. (1992). Theoretical perspectives for strategic human resource management. Journal of Management, 18, 295-320. 